\title{
COMMUNICATION
}

\section{Todos Cuentan: Cultivating Diversity in Combinatorics}

\section{Federico Ardila-Mantilla}

In nine years the Combinatorics Initiative between San Francisco State University (SFSU) and the nation of Colombia has built an active community of more than two hundred mathematicians, most of whom are members of underrepresented groups in mathematics. More than fifty have pursued PhDs in mathematics, while others continue to be mathematics users, enthusiasts, and ambassadors in other fields and to encourage and inspire the next generation of scientists in their communities. This article tells our story and shares some lessons we have learned about broadening and deepening representation in mathematics.

We begin by stating our axioms in the first section. We then outline our work in "SFSU-Colombia Combinatorics Initiative" and discuss our underlying sociopolitical framework and pedagogical strategies in "Deepening Representation."

\section{The Axioms}

Let me begin with some axioms. I firmly believe in them, and I build my work upon them.

Axiom 1. Mathematical talent is distributed equally among different groups, irrespective of geographic, demographic, and economic boundaries.

Axiom 2. Everyone can have joyful, meaningful, and empowering mathematical experiences.

Axiom 3. Mathematics is a powerful, malleable tool that can be shaped and used differently by various communities to serve their needs.

Axiom 4. Every student deserves to be treated with dignity and respect.

These statements should not sound revolutionary, but considering the current practices of the mathematical society, they are a pressing call to action.

\footnotetext{
"Todos cuentan" means "Everybody counts."
}

Federico Ardila-Mantilla is professor of mathematics at San Francisco State University and adjunct professor at Universidad de Los Andes, Colombia. His email address is federico@sfsu. edu.

For permission to reprint this article, please contact:

reprint-permission@ams.org.

DOI: http://dx.doi.org/10.1090/noti1434

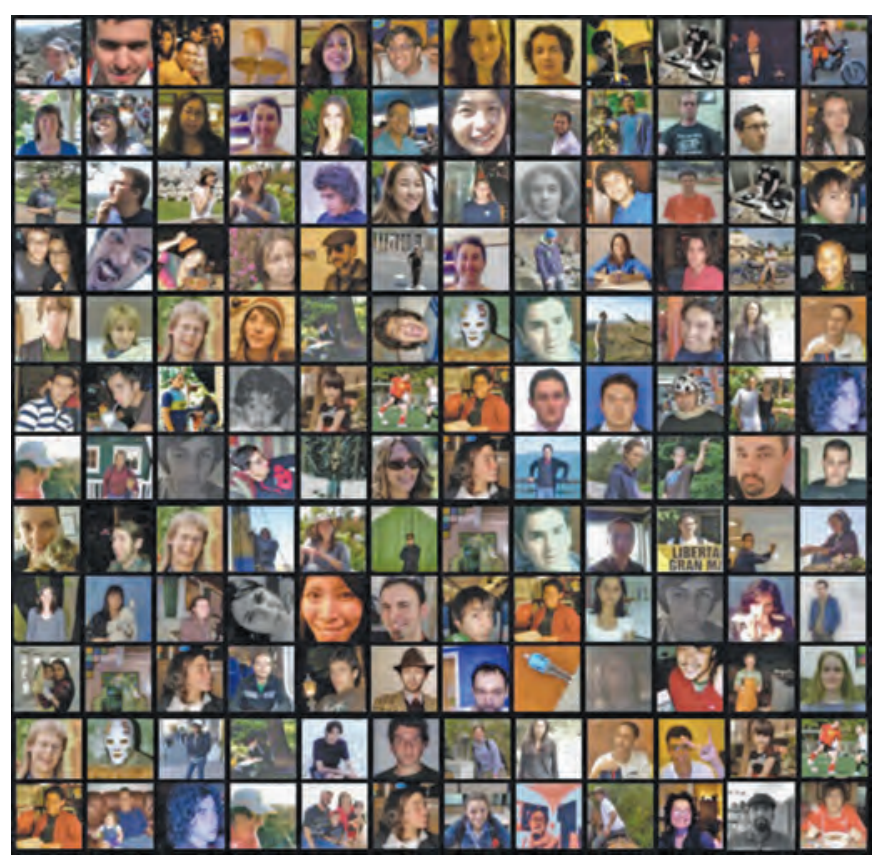

Figure 1. A diverse group of more than two hundred mathematicians comprises the SFSU-Colombia Combinatorics Initiative.

\section{SFSU-Colombia Combinatorics Initiative}

The SFSU-Colombia Combinatorics Initiative is a research and training collaboration that seeks to offer every interested student a challenging and supportive mathematical experience while planting seeds for the broader and deeper representation of different groups in mathematics.

\section{The Partners}

The Universidad de Los Andes is an elite private university in Colombia. Its math department is one of the country's strongest, and through scholarships it attracts some of the best-prepared students in the country. Most Los Andes participants in the program are undergraduates with very solid mathematics backgrounds but little understanding of what research looks like. About one fifth of them were members of the Colombian math olympiad team, which I coached for fifteen years.

SFSU is a large public four-year university with a diverse population: over 60 percent of the students 
come from ethnic minority groups, and almost half are first-generation college students. The Masters program welcomes and serves a student body with a wide range of demographics and academic preparation. SFSU is home to an active research group in combinatorics, including about fifteen research students at a time.

I was born and raised in Colombia, discovering mathematics through the Olimpiadas Colombianas de Matemáticas. I came to the US twenty-two years ago as an undergraduate on a scholarship to MIT and have been here ever since while remaining in close contact with Colombia and its mathematics. In the US I am usually counted as a minority mathematician, and I have often felt in the minority. Though I was treated well, most of my training in the US took place alone, avoiding mathematical spaces where I felt uncomfortable. However, unlike most students from marginalized groups in mathematics, I never had to overcome the structural inequalities of our educational system. In particular, I never had a teacher or peer who doubted my abilities or told me that I was not good enough to succeed.

\section{How it All Started (2005)}

Felipe Rincón, then an undergraduate at Los Andes, had taken my Algebraic Combinatorics course there in 2003 and was writing his thesis under my supervision. In view of his classmates' interest and the relative lack of activity in this field in Colombia, he volunteered to teach an unofficial combinatorics course for free. The course was a great success, attracting more than twenty of the approximately one-hundred twenty math majors.

I had recently begun an assistant professorship at San Francisco State University and was very interested in contributing to mathematics in Colombia. Felipe's course exposed a great need, so I decided to offer a follow-up topics course on matroid theory, offered jointly at SFSU in person and at Los Andes electronically. Internet courses were still not in fashion, and this was exactly the kind of wild, uncertain experiment that Colombians love to embark upon.

\section{SFSU/Los Andes, Matroid Theory (2007)}

I taught the class at SFSU and filmed it using my colleague Arek Goetz's wonderfully low-budget artisanal setup, modeled after the one used by his figure-skating sister: heat sensors across the front of the room detected where I was standing and told the camera in the back where to point. With practice I learned to use large and clear handwriting and to move around less so I would not make the viewers dizzy. Arek also improved his algorithm so the camera would not follow me when I walked across the room and back to get the eraser.

Los Andes students watched the lecture together in a classroom, where I was present virtually to answer questions. We could not meet simultaneously due to time zone differences and the limits of the technology available to us. I visited Bogotá early in the semester to meet the students in person. PhD students from UC Berkeley also took the class, some in person and some on video.
We made great efforts for US and Colombian students to feel that they were in the same class. Students created mini-bios, including their photos, personal background, and mathematical interests; they were not afraid to let their personalities shine through. I also created an online forum where students from US and Colombia got to "meet," discuss the course material and the assignments, and find future collaborators.

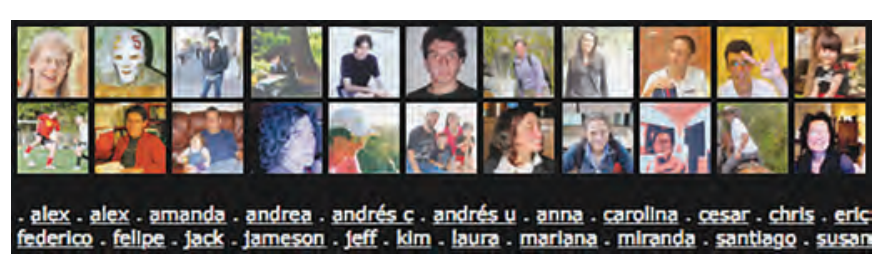

Figure 2. Student profiles from the 2007 matroid theory joint course, the first course offered as part of the SFSU-Colombia Combinatorics Initiative.

In the first half of the course I assigned homework that ranged from reasonably straightforward exercises, accessible to anyone in the class, to approachable but challenging recent results in the matroid theory literature which required extensive (sometimes international) teamwork. Occasionally I assigned unannounced open problems. Posting student solutions while trying to represent everyone in the class raised the quality of the work and the writing. Most but not all Colombians were proficient in English, and some took the opportunity to write mathematics in English for the first time. Others didn't, and SFSU students got to read mathematics in Spanish; this was especially exciting for some of the US Latinas/os, many of whom spoke Spanish at home but not in their mathematical life.

In the second half, students did final projects in pairs; I suggested projects ranging from surveys of classic topics to current open problems of interest. Most students tried to do original research; see Figure 3.

- Results. The eleven projects in the class led to five papers in international journals (three coauthored internationally) and eight theses. Nine years later, of the twenty-one students in the class, eleven have completed PhDs in mathematics. Currently,

- four are university professors in mathematics,

- six are postdoctoral researchers in mathematics,

- four are community college faculty in mathematics,

- two are PhD students in economics, and

- five are working in industry.

- Observations and lessons learned

- Every student did deep work, especially in their final projects. Students with substantial mathematical gaps learned what they needed along the way.

- A strong sense of teamwork and collaboration helped most students lift one another up, though a few struggled with having to do mathematics in groups. 

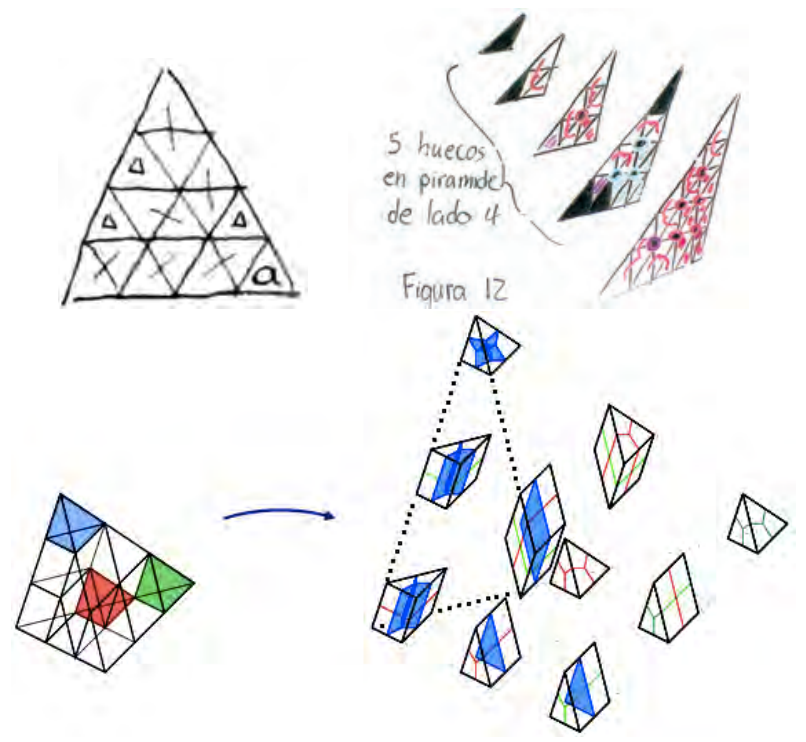

Figure 3. Cesar Ceballos's research, motivated by work of Billey and Vakil on the Schubert calculus of the flag variety, progresses from a homework solution to a final project and a publication about the triangulations of a product of two simplices $\Delta_{m} \times \Delta_{n}$.

- Most projects were international, and those were most productive. Students' curiosity towards and accountability to strangers played a useful role.

- Generally speaking, SFSU students were impressed with the knowledge and problem-solving skills of Los Andes students. Los Andes students were impressed by the work ethic and determination of SFSU students, particularly in their research projects.

- Asynchronicity was far from ideal; it made classes lecture-centric. Creating a coherent shared experience took hard work, and it was still not a great substitute for personal interaction.

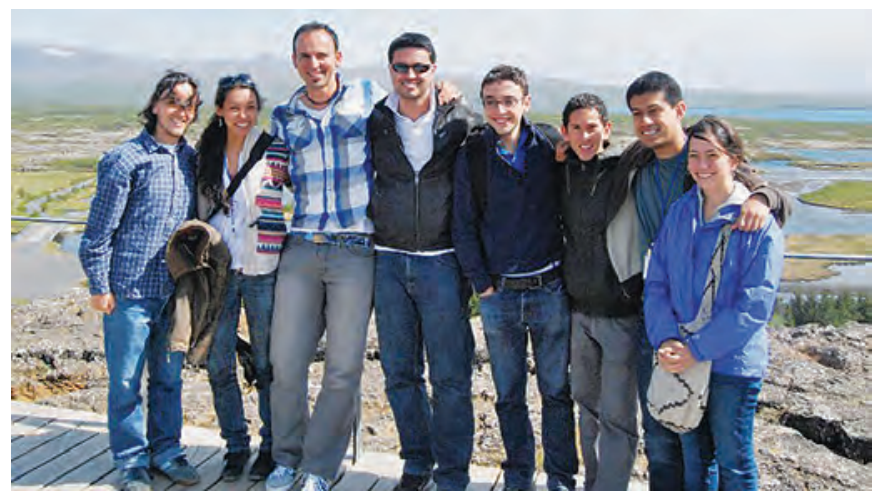

Figure 4. Ardila-Mantilla with some of the Colombian researchers presenting their work at the FPSAC 2011 combinatorics conference in Iceland.

${ }^{1}$ For a list of publications of students in the SFSU-Colombia Combinatorics Initiative, visit math.sfsu.edu/federico/ SFSUColombia/papers.htm7.
Some Guiding Principles for the Course Design

The Matroid Theory class became the blueprint for eight topics courses over the last nine years; six of them were offered jointly at SFSU and Los Andes. As I continued to design these courses, I identified a few key principles that I always attempted to implement.

- Choose a deep topic of current interest that is accessible to students with different backgrounds.

- Hold students to extremely high standards and match that expectation with a solid support system.

- Devise challenging, interesting, and inspiring assignments, including a final project in pairs that students have the freedom to design themselves.

- Give students the time they need: allow two weeks for each homework and two months for the final project.

- Create a course structure that builds a strong community through a shared mathematical purpose.

Several student evaluations mentioned this sense of community, and some took it to social media:

Jeffrey Doker shared a link via Federico Ardila.

about an hour ago $\$$ s

Out of all the math classes I've taken over the years one of them affected my life more than any of the others. Federico Ardila (who became my coauthor, dissertation advisor, and friend) started a fire in our crew of lovable eccentrics and when it was all over we had published original research and made lifelong friendships across continents. We all became mathematicians and we all loved each other and we all still do.

That class was recorded, and here it is.

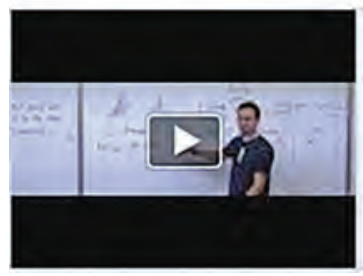

Federico Ardila: Matroids

A Spring 2007 course on Matroids at SFSU and Los Andes taught by

Federico Ardila. "* A lecture index is coming soon. $* 1$ have taught 5 joint courses: - Matroids (2007) - Coxeter

\section{Online Resources}

I made all materials for my six SFSU-Colombia courses freely available, including more than 240 hours of videos on the YouTube channel federicoelmatematico. According to the channel's statistics, users in 155 countries have viewed more than 10,000 hours of combinatorics videos. More meaningful to me, I have personally heard from active users in places like Colombia, Germany, India, Iran, Sudan, Turkey, and the United States.

Technology offers exciting possibilities to increase access to education, but we should be cautious in interpreting the numbers above. For example, the average view duration for these 50-75-minute videos was 8:33. Of the viewers who divulged their gender, 81 percent were men. The last few lectures of each course were watched between 60 and 300 times each, with viewers concentrated in the US and Western Europe and including several of 
my students and colleagues. These online resources have certainly been helpful to people, but I do not believe they have had a significant effect in closing the gap for access to quality mathematics resources.

\section{Encuentro Colombiano de Combinatoria (ECCO)}

It soon became clear that US and Colombian students wanted to build closer ties and collaborate in person. I organized the Encuentro Colombiano de Combinatoria to benefit young mathematicians first and foremost, especially those who do not have easy access to such an opportunity. Now organized by a committee of former participants, ECCO meets bi-yearly. We do our best to build an atmosphere that is equally professional, welcoming, inclusive, and joyful. The reader may find Viviane Pons's personal account of her experience at ECCO 2016 in the AMS blog On Teaching and Learning Mathematics. ${ }^{2}$

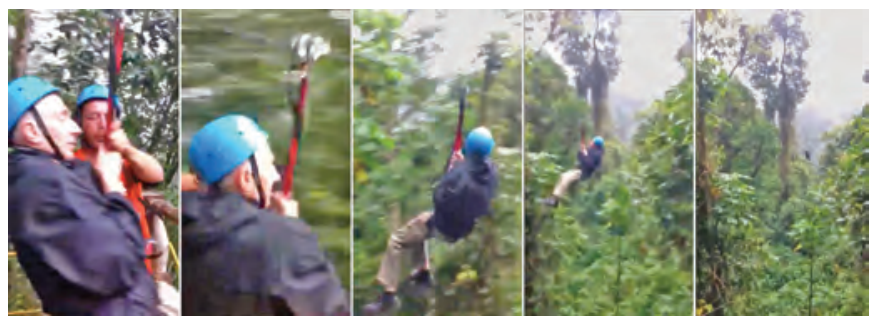

Figure 5. MIT professor Richard Stanley as he is about to zipline across the Chicaque Cloud Forest with US and Colombian students during ECCO 2014: "I hope I don't have a heart attack right now; I still have to go to my birthday conference next week!"

ECCO features minicourses by international experts. Each minicourse lecture is followed by a problem session in randomly chosen groups that include mathematicians of varying levels of experience; see Figure 6. This forces every participant to engage with every topic and allows young people to meet and work with many experienced researchers and see how they approach unfamiliar topics. It also gives the lecturers immediate feedback on their course and allows them to adapt accordingly. ECCO also features research talks by students, open problem presentations, mentoring sessions, a visit to a salsa dance club, a hike, and (inevitably it seems) an impromptu street party.

ECCO 2016 was a CIMPA Research School and hosted 130 participants from over twenty countries, mostly from Latin America. Now that ECCO has gained some international notoriety, several combinatorics experts have asked to attend. We welcome them with care, reminding them that this is a school and an encuentro, ${ }^{3}$ not a regular conference. We ask these experts to do problem sets with the students, to present open problems that they would like help with, to serve as mentors, and probably to join the dance floor at some point. They have been

${ }^{2}$ ViViane PONS, "An Inclusive Maths Conference, ECCO 2016," AMS blog On Teaching and Learning Mathematics, August 22, 2016.

${ }^{3}$ gathering, usually of people with shared experiences

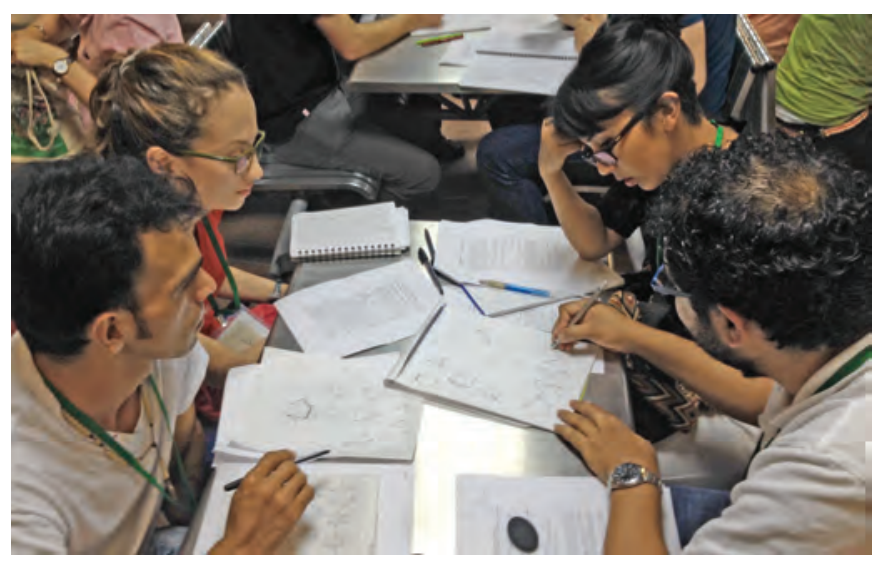

Figure 6. A team of mathematicians from Universidad del Amazonas, Universidad del Cauca, University of Kentucky, and Fundación Universitaria Konrad Lorenz working on a problem set in discrete geometry during ECCO 2016.

wonderfully helpful and inspiring mentors, and several have mentioned that their experiences at ECCO have influenced their work at their home institutions.

I consider it a success that I am no longer on the ECCO organizing committee; sharing the decision making has brought new energy, ideas and perspectives, and has given many people a sense of ownership of this project. More importantly, I believe it has fostered their agency as members of the mathematical society and empowered them to pursue their own initiatives.

\section{Funding}

The Matroid Theory class and ECCO 2008 were generously funded by seed grants from SFSU and Los Andes. With those results in hand, I applied for the NSF CAREER and Combinatorics grants that have funded our activities since then.

The cost of tuition and living in San Francisco is a real challenge for our students, most of whom have significant workloads while they study. We have supported some of them using other NSF and NIH grants at SFSU, such as Matt Beck's GK-12 grant in mathematics and Frank Bayliss's SEO grants in science. We plan to implement a more sustainable funding infrastructure that will allow our students to better focus their efforts on their academic preparation.

\section{Some Statistics}

Approximately 200 students have officially enrolled in the classes offered by this initiative, and approximately 50 of them have pursued $\mathrm{PhDs}$ in the mathematical sciences.

The initiative has had 40 thesis students ( $4 \mathrm{PhD}, 27$ MS, 12 BS): 28 in the US (14 women, $15 \mathrm{URMs}^{4}$ ) and 12 in Colombia (3 women, 12 URMs), who authored more than 20 publications, which appeared in journals such as Duke Mathematical Journal, Advances in Mathematics, International Mathematics Research Notices, and Journal of Combinatorial Theory, Series A.

\footnotetext{
${ }^{4}$ underrepresented minorities
} 
Of these 40 students, 28 have entered math $\mathrm{PhD}$ programs (19 US, 11 women, 21 URMs), and 25 have finished or are current students, including all 21 URMs. $^{5}$

\section{Deepening Representation}

The underrepresentation of women, Latinas/os, and African Americans in US mathematics is well documented. ${ }^{6}$ These groups constituted respectively:

- 50.8 percent, 17.4 percent, 13.2 percent of the 2014 population [10];

- 31 percent, 3.5 percent, 2.5 percent of the 2014 new math PhDs [11];

- 18 percent, 3 percent, 1 percent of the full-time math faculty at PhD-granting institutions in 2005 [2].

Underrepresentation is more drastic further along the academic career. Among the science, engineering, and health faculty in 2008, Latinas/os and African Americans constituted 4.8 percent and 5 percent of assistant professors, 3.6 percent and 4.8 percent of associate professors, and 3.3 percent and 2.3 percent of full professors [1].

These numbers naturally lead to further underrepresentation in positions of leadership and decision-making power, slowing down the changes necessary to reverse this trend. Within the AMS, all sixty-three presidents have been white and sixty-one have been men. The situation is improving: the twelve current officers include four women and two foreign-born Latinos. A new Directorship of Education and Diversity was instituted in 2016, and To truly broaden $\begin{aligned} & \text { roots level, many } \\ & \text { excellent Mathematics }\end{aligned}$ representation we Programs That Make a must deepen
representation Difference have been recognized since 2006 . However, the mathematical society at large still has a lot of work to do.

It appears that, now more than ever, US society recognizes the importance of building a scientific workforce that reflects and represents our diverse demographics. It is less clear how this will be achieved, but we have learned a few things: it is not enough to wait for the occasional lone "geniuses" from unlikely places to make it against all odds; it is not enough to say that we don't see gender or race in our classrooms; it is not enough to offer a few different kinds of people entrance to the same old house and expect them to come in and to thrive. To truly broaden representation we must deepen representation. We must be prepared to truly accept the structural inequalities that led to the current state of affairs, both within our mathematical population and in society at large, and to do the deep, hard work that is required to overcome them. As a mathematician with rather limited knowledge and expertise, I find this a daunting challenge.

\footnotetext{
${ }^{5}$ Numbers for US and women omitted for confidentiality.

${ }^{6}$ We focus for the moment on these three large groups for which data is available.
}

As scientists do when faced with a seemingly intractable problem, I have focused on a smaller problem for the moment: building nurturing environments where different people can thrive and do excellent mathematics. I certainly don't have a recipe for how to do this, and I know we still have a long way to go, but I do think the SFSUColombia Combinatorics Initiative has achieved some success. Along the way, by listening to students, teachers, organizers, and scholars, I have learned a few things about the larger structural obstacles to be overcome. I believe the following factors have been crucial to the small successes we've had so far.

\section{The Mathematics}

To succeed in mathematics, one must do high-quality mathematics. This is especially true for students without elite credentials, for whom the bar to success is often set higher. It is crucial to involve mentors with active research programs in areas of current interest.

\section{Todos Cuentan (Everybody Counts)}

Our activities are designed to serve every interested student by building an inclusive environment that everyone contributes to and benefits from. We aim to increase students' sense of belonging and responsibility to their mathematical community; see the "Agreement" section in Figure 7.
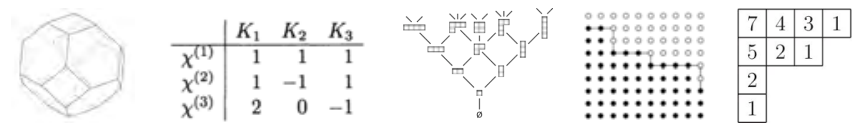

math 850 . representation theory

san francisco state university federico ardila

Agreement. The goal of this course is to offer a meaningful, rigorous, and rewarding experience to every student; you will build that rich experience by devoting your strongest available effort to the class. You will be challenged and supported. Please be prepared to take an active, patient, and generous role in your own learning and that of your classmates.

Diary. After class $n$ you will discuss the material with a classmate, and turn in a very brief summary of the key points at the beginning of class $n+1$. We will begin class $n+1$ by discussing these. After class $n+1$, you will edit and transcribe your summary of class $n$ into your "diary" in LaTeX. You will get extra credit if you write diary entries with $>2 / 3$ of the students in the class. Final Project. This is a chance to go much deeper into a topic that interests you, in pairs. It could be an expository paper, the beginning of an original research project, or (why not?) the solution to an open problem. I will suggest possible projects. For most of you, this is the first time you receive such an open-ended assignment in a mathematics class. Have fun with it! Don't be afraid to take a risk; this is an opportunity to try something intriguing that you don't know how to do.

Figure 7. Syllabus excerpt of our Representation Theory course. We make sure students know they will be challenged and supported.

Intentionally or not, most programs in higher mathematics are designed to select the "top" mathematicians at each stage and prepare them for the next stage. Such programs have certainly played a crucial role in the careers of many mathematicians, including mine. However, they have also played a role in excluding and discouraging others with great mathematical potential, particularly among underrepresented groups.

\section{Equitable Spaces}

We try to be mindful of how different students experience the same environment and find ways to make sure each 
one of them is actively involved and engaged within the spaces we provide.

Language matters. Many of the standard patterns of communication of mathematicians-like calling a fact "easy to see" when it isn't, or saying "I get it" when one doesn't-are harmless to some, but they feel exclusive to those who already feel like outsiders.

Structure matters. Without an explicit and mindful effort, classrooms easily turn into conversations between a professor and a handful of students. My current courses are organized so that every student participates in every class, either verbally, in writing, or in small groups; I use several of Kimberly Tanner's techniques for creating equitable learning environments [8].

\section{The Support System}

A challenging experience can easily become alienating if it is not presented mindfully and accompanied with abundant support. We do not shy away from the emotional side of this work. A career in mathematics requires balancing long periods of frustration with (sometimes too brief) moments of great joy, and students find it surprising and beneficial to learn that they are not the only ones struggling with that balance. Readings and discussions on the psychology of mathematics and science [7], [9], growth mindset [4], stereotype threat [6], and impostor syndrome [3] have been helpful.

At SFSU we collaborate with initiatives like SF BUILD, which works to create inclusive and supportive research environments across six science departments, and the Mathematistas student group for women in math, which builds community in our department through many informal activities. Outside SFSU we benefit from interacting with organizations such as SACNAS, the Math Alliance, USTARS, and Latin@s in Math.

We are aware that the crucial work of supporting students traditionally falls disproportionately on women and people of color [12]. We make every attempt to counter that tendency.

\section{People Rise to High Expectations}

Many of my students from marginalized groups have been told, often by well-meaning professors in positions of power over them, that they cannot do something or that they are not good enough to be mathematicians. I never say this to a student. I cannot possibly know that. ${ }^{7}$

I have worked with students whose mathematical potential is not immediately apparent to me, but I know they are here for a reason. My approach is to always treat them with respect, give them an intriguing project that suits their experience and interests, and support them along the way; I have seen most of them rise to that challenge.

\footnotetext{
${ }^{7}$ Upon meeting Endre Szemerédi, Israel Gelfand told him, "Just try to find another profession; there are plenty in the world where you may be successful" [5]. Szemerédi went on to write his PhD thesis under Gelfand and win the 2012 Abel Prize.
}

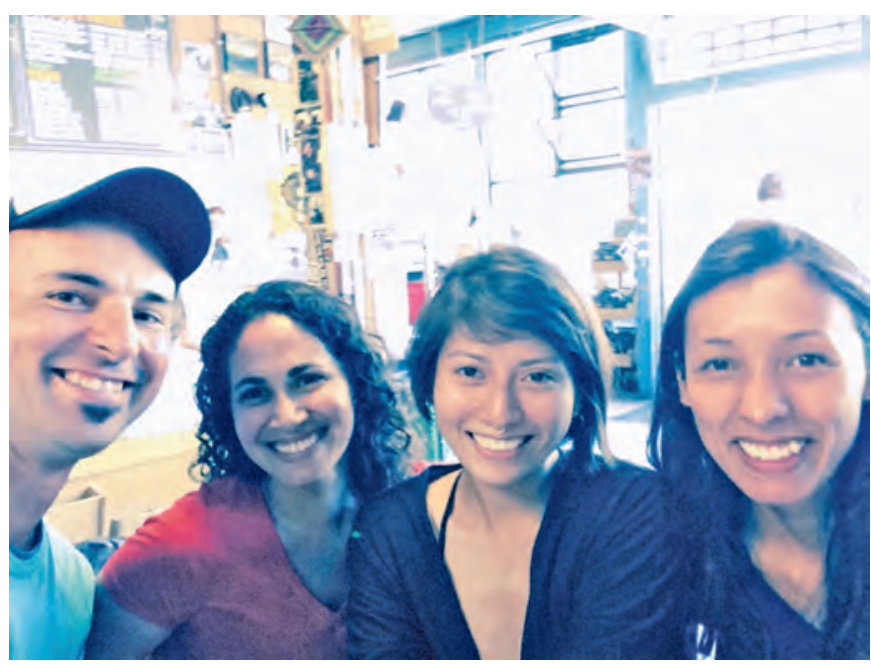

Figure 8. Celebrating Anastasia Chavez and Nicole Yamzon's new theorem on the Dehn-Sommerville relations, Carolina Benedetti's visit to San Francisco, and Nicole's birthday. L to R: Ardila-Mantilla, Chavez, Yamzon, Benedetti.

\section{Unconscious Bias and Discrimination}

The mathematical society at large is relatively homogeneous, and students who do not fit neatly within its dominant cultures are often faced with unspoken but real obstacles. This is especially true for many underrepresented minorities, women and gender minorities, parents, disabled, low-income, first-generation, and returning students among others. On a professional level, these students face skepticism, and their work is undervalued by professors and peers. On a personal level, many feel pressured to leave their true selves at the door to try to fit in.

These are deep problems that we are far from solving. When they do arise, we talk about them openly, learn from them, and try to improve. We also emphasize that this is not just a problem for marginalized groups to address; every member of the mathematical society plays a role.

\section{The Bigger Picture}

The SFSU-Colombia Combinatorics Initiative tries to instill an awareness of the tremendous power that mathematicians hold in today's society and a collective belief in using our part of that power to do positive work. Individuals get to decide what this means for them, whether or not they pursue careers in mathematics. For many of them it means planting the seeds for the next generation of scientists in their communities. Today's uneven representation in mathematics is largely, though not exclusively, a consequence of the uneven access to opportunities before students arrive in our college classrooms. Several of our students and alumni are doing powerful work with young people at various stages of their education. We are slowly integrating their initiatives through a network of mentorship that everyone contributes to and benefits from.

In Colombia several participants in the initiative supervise undergraduate research projects and lead math 
olympiad programs. Others partner with the Clubes de Ciencia Colombia and the interactive science museum Parque Explora; thanks to them, ECCO 2016 included a week-long workshop for students in Medellín public schools and a public math talk featuring the students' work that was broadcast by television and internet stream. ${ }^{8}$

In the United States participants direct the San Francisco Math Circles, making great efforts to reach the (88 percent ethnic minority) populations of the San Francisco Unified School District. Through the GK-12 program, fifty PhD-bound students spent ten hours a week supporting the mathematics departments of various local public high schools. Other alumni teach mathematics full-time in local community colleges and high schools; the school district claims that 70 percent of its teachers have received training at SFSU.

I am inspired to be surrounded by a family of mathematicians who are doing extremely interesting mathematics and see themselves as agents of change in our scientific culture and in our societies. We are working hard to train the next generation of scientists-a diverse, engaged, dynamic community that works to serve the needs of all-and we are having a lot of fun in the process.

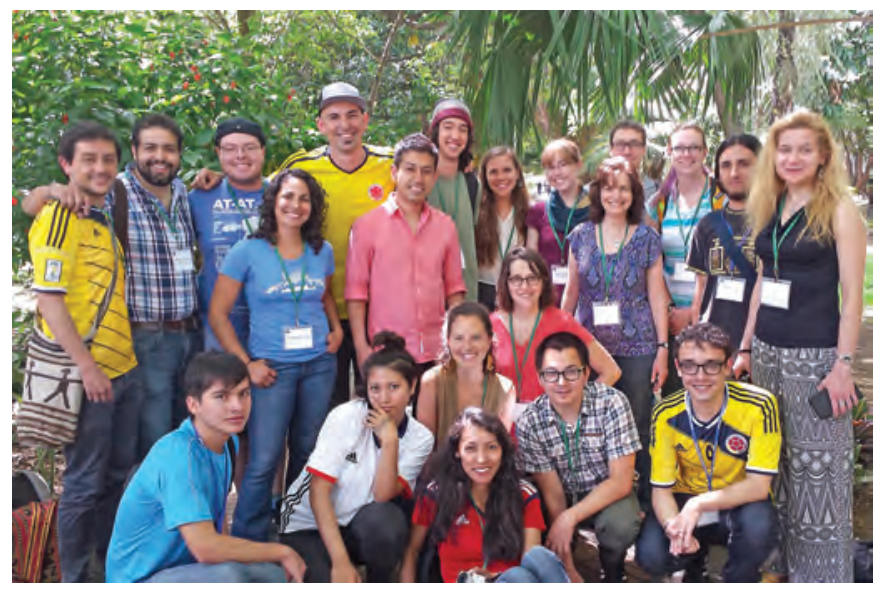

Figure 9. Members and friends of the SFSU-Colombia combinatorics community in Medellín, Colombia. More Information

Our webpage, containing additional information and resources, can be found at:

math.sfsu.edu/federico/sfsucolombia.html

\section{Acknowledgments}

I thank the AMS Committee on Education, AMS president Robert Bryant, and the editors of the Notices of the AMS for inviting me to organize and share my ideas around a topic that is very challenging to me, partly because it is also very personal to me.

I am just one of many people doing this work at San Francisco State University and in Colombia. I am indebted to my colleagues for their invaluable support of this project. This work has also been supported by the NSF CAREER Award DMS-0956178, the NSF Combinatorics Grants DMS-0801075 and DMS-1600609, and the NIH SF BUILD grant 5UL1GM118985-03.

If I have learned one thing, it is that I still have a lot to learn. I am extremely grateful to the teachers, colleagues, family members, friends, organizers, and futbolistas who have shaped this initiative; I must mention Natalia Ardila, Matthias Beck, Ben Braun, Dania Cabello, Jeff Duncan-Andrade, Piper Harron, May-Li Khoe, María de Losada, Amparo Mantilla de Ardila, Leticia Márquez-Magaña, Bob Moses, Ali Nesin, Gustavo Salazar, Kimberly Tanner, and Nicole Yamzon. Most importantly, I would like to thank my students, who teach me something new every day and give meaning to my mathematical career.

\section{References}

[1] JOAN BURRELLI, Academic institutions of minority faculty with science, engineering, and health doctorates, National Science Foundation InfoBrief, NSF 11-320, October 2011, www.nsf.gov/statistics/infbrief/nsf11320/.

[2] RiCHELle Blair, Ellen E. KiRKMAN, and JAMES W. MAXWELL, Statistical Abstract of Undergraduate Programs in the Mathematical Sciences in the United States, American Mathematical Society, 2013.

[3] Pauline Rose Clance and Suzanne Imes, The imposter phenomenon in high achieving women: Dynamics and therapeutic intervention, Psychotherapy: Theory, Research and Practice 15 (1978), 241-247.

[4] CARol DwEck, The secret to raising smart kids, Scientific American Mind 18 (2007), 36-43.

[5] MARTIN RAUSSEN and CHRISTIAN SKAU, Interview with Endre Szemerédi, Notices Amer. Math. Soc. 60 (2013), 221-231. MR 3060028

[6] Claude Steele, Whistling Vivaldi: And Other Clues to How Stereotypes Affect Us, W. W. Norton and Company, New York, 2010.

[7] MARTIN A. SCHWARTZ, The importance of stupidity in scientific research, Journal of Cell Science 121 (2008), 1771.

[8] Kimberly TANNER, Structure matters: Twenty-one teaching strategies to promote student engagement and cultivate classroom equity, CBE-Life Sciences Education 12 (2013), 322-331.

[9] WiLliam ThuRston, On proof and progress in mathematics, Bull. Amer. Math. Soc. 30 (1994), 161-177. MR 1249357

[10] United States Census Bureau, https://www. census. gov/quickfacts/table/PST045215/00, 2014, accessed June 11, 2016.

[11] William Yslas VÉlez, James MaXwell, and ColleEn Rose, Report on the 2013-2014 new doctoral recipients, Notices Amer. Math. Soc. 62 (2015), 771-781.

[12] AUDREY Williams JunE, The invisible labor of minority professors, The Chronicle of Higher Education (November 8, 2015).

\section{Credits}

Part of Figure 3 is courtesy of Cesar Ceballos.

Figure 5 is courtesy of May-Li Khoe.

Figure 9 is courtesy of Mark Skandera.

Screen shot image on matroids is courtesy of Jeff Doker.

8 iivestream.com/ParqueExploraTV/Fisica/videos/127505227 